\title{
Stoichiometry effect on the irradiation response in the microstructure of zirconium carbides
}

\author{
Yong Yang ${ }^{a, *}$, Wei-Yang Lo ${ }^{a}$, Clayton Dickerson ${ }^{b}$ and Todd R. Allen ${ }^{c, d}$ \\ ${ }^{a}$ University of Florida, Nuclear Engineering Program, Gainesville, FL 32611, USA, " yongyang@ufl.edu \\ ${ }^{b}$ Argonne National Laboratory, IL, USA \\ ${ }^{c}$ University of Wisconsin-Madison, Department of Engineering Physics, Madison, 53706 USA \\ ${ }^{d}$ Idaho National Laboratory, Idaho Falls, ID 83415, USA
}

\begin{abstract}
Zone-refined ultra high pure $\mathrm{ZrC}$ with five $\mathrm{C} / \mathrm{Zr}$ ratios ranging from $0.84-1.17$ was irradiated using a $2 \mathrm{MeV}$ proton beam at $1125^{\circ} \mathrm{C}$. The stoichiometry effect on the irradiation response of $\mathrm{ZrC}$ microstructure was examined using transmission electron microscopy following the irradiation. The irradiated microstructures generally feature a high density of perfect dislocation loops particularly at away from the graphite precipitates, and the $\mathrm{C} / \mathrm{Zr}$ ratio shows a notable effect on the size and density of dislocation loops. The dislocation loops are identified as interstitial type perfect loops, and it was indirectly proved that the dislocation loop core likely consists of carbon atoms. Graphite precipitates that form with excess carbon in the superstoichiometric $\mathrm{ZrC}$ are detrimental, and the dramatic increases in the size of and density of dislocation loops in the vicinity of graphite precipitates in $\mathrm{ZrC}$ phase were observed. Irradiationinduced faceted voids were only observed in $\mathrm{ZrC}_{0.95}$, which is attributed to the pre-existing dislocation lines as biased sinks for vacancies.
\end{abstract}




\section{Introduction}

$\mathrm{ZrC}$, with a cubic $\mathrm{NaCl}$ type crystal structure, has high melting point, exceptional hardness and good thermal and electrical conductivities. A comprehensive review on the properties of $\mathrm{ZrC}$ for nuclear fuel application was recently published by Katoh, et al. [1]. $\mathrm{ZrC}$ has been considered for the deep burn TRISO (Tristructural-isotropic) fuel as an oxygen getter in the kernel, a coating layer for fission product retention, or a combination of these two functions as a direct coating on the fuel kernel. As a component of the TRISO fuel particle, $\mathrm{ZrC}$ is expected to experience high dose irradiation under the fuel operating temperature ranging from 850 to $1350{ }^{\circ} \mathrm{C}$ in a high temperature gas-cooled reactor (HTGR) [2]. Beside its potential nuclear fuel and nuclear propulsion applications, $\mathrm{ZrC}$ was also considered for many other industrial applications attributed to its high temperature stability and extreme hardness at room temperature.

Historically, the irradiation effects on $\mathrm{ZrC}$ were quite poorly understood and the majority of the available data were from the temperatures well below $850{ }^{\circ} \mathrm{C}$ [3-8]. Our previous work on commercial grade $\mathrm{ZrC}_{1.01}$, proton irradiated at $800{ }^{\circ} \mathrm{C}$, reveals that the irradiated microstructures are dominated with a high density of faulted dislocation loops, and slight changes in the lattice parameter, hardness and fracture toughness were also observed [4]. More recently, Snead et al. [9] studied zone-refined $\mathrm{ZrC}_{0.93}$ irradiated with fast neutrons over a temperate range of $635-1480{ }^{\circ} \mathrm{C}$. The microstructures were dominated with dislocation loops which gradually evolved from Frank loops to perfect loops as the irradiation temperature increased above $1280{ }^{\circ} \mathrm{C}$.

It was widely reported that the properties of $\mathrm{ZrC}_{\mathrm{x}}$ are often sensitive to the stoichiometry $(\mathrm{C} / \mathrm{Zr}$ ratio) [10], and based on the Zr-C phase diagram (Fig. 1) [11], the carbon stoichiometry " $\mathrm{x}$ " ranges from slightly less than 0.6 to $\sim 1.0$. The high concentration of carbon vacancies or excessive graphite precipitates can significantly affect the various properties of $\mathrm{ZrC}_{\mathrm{x}}$, and the 
effect of $\mathrm{C} / \mathrm{Zr}$ ratio on microstructures and properties was summarized by Katoh, et al. [1]. The irradiation behavior is very likely affected by the $\mathrm{C} / \mathrm{Zr}$ ratio. As a potential candidate coating layer for replacing the $\mathrm{SiC}$ coating of the Triso-coated fuel particle, the fabrication of $\mathrm{ZrC}$ coating has been investigated using chemical vapor deposition (CVD) methods by a number of groups [12-14], and it was revealed that the stoichiometry of the $\mathrm{ZrC}$ coating is very sensitive to the processing route and conditions and the $\mathrm{ZrC}$ deposited by $\mathrm{CVD}$ tends to have a hyperstoichiometric $\mathrm{C} / \mathrm{Zr}$ ratio. Therefore, it will be pertinent to systematically study the radiation response over a range of stoichiometry, and it is speculated that the radiation damage to substoichiometric materials is relatively less than the nearly-stoichiometric or hyper-stoichiometric ones since the large number of carbon vacancies may provide a sink for irradiation produced defects in sub-stoichiometric $\mathrm{ZrC}$.

This work investigated the effect of stoichiometry on the radiation response of high-purity $\mathrm{ZrC}$ irradiated at HTGR relevant temperature. The fundamental understanding on the radiation response over a range of stoichiometry will provide a baseline for a practical fabrication of $\mathrm{ZrC}$ Triso (ZRISO) particle fuel from the aspect of radiation behavior.

\section{Experiments}

A series of high purity, zone-refined $\mathrm{ZrC}$ samples were provided by Oak Ridge National Laboratory (ORNL), and the materials were fabricated by Applied Physics Technologies, Inc. McMinnville, Oregon. These samples were prepared with five nominal $\mathrm{C} / \mathrm{Zr}$ atomic ratios ranging from 0.8 to 1.2 . As listed in Table 1 , the overall bulk $\mathrm{C} / \mathrm{Zr}$ ratios were determined by the vendor using mass-percent carbon analysis, and these ratio will be used to identify each material. The exact $\mathrm{C} / \mathrm{Zr}$ ratio in the $\mathrm{ZrC}_{\mathrm{x}}$ matrix was determined using a JEOL 733 Superprobe equipped 
with wavelength dispersive spectrometers (WDS). Consistently with the phase diagram, for the materials with a $\mathrm{C} / \mathrm{Zr}$ ratio above one, the $\mathrm{ZrC}$ matrix is nearly stoichiometric with excessive carbon as graphite precipitates.

A set of $3 \mathrm{~mm}$ discs with a nominal $350 \mu \mathrm{m}$ thickness were sliced from the $\mathrm{ZrC}$ rods and then mechanical polished down to a final finish of $50 \mathrm{~nm}$ using silica colloid for proton irradiation experiment. The proton irradiation was conducted using a Tandem accelerator the beam energy of $2 \mathrm{MeV}$. All the samples were irradiated in the same irradiation batch with two discs for each stoichiometry. The damage profile for the stoichiometric $\mathrm{ZrC}$, calculated using TRIM2013 (Transport of Ions in Matter) [15] with the threshold displacement energies of $35 \mathrm{eV}$ for zirconium and $25 \mathrm{eV}$ for carbon, is shown in Fig. 2. Those threshold energies were used by Gosset [6] and they were based on the values observed in TaC. The K-P model was used the dpa (displacement per atom) calculation. The depth of the greatest interest is the shadowed region of 10-15 $\mu \mathrm{m}$ from the sample surface, and this region has a relatively constant radiation damage level. A fluence of $2.0 \times 10^{19}$ protons $/ \mathrm{cm}^{2}$ was achieved, which corresponds to $2 \mathrm{dpa}$ for the stoichiometric $\mathrm{ZrC}$ with a dose rate of approximately $1.8 \times 10^{-5}$ dpa/s. Fig. 2 also shows the distribution of the measured irradiation temperature with a mean of $1125{ }^{\circ} \mathrm{C}$. During the irradiation, the temperatures were monitored by two stage-embedded thermocouples, and the tips of thermocouple were spot-welded on the backsides of two Mo dummy discs that were irradiated together with the $\mathrm{ZrC}$ discs. The experimental temperature was achieved by heating the sample with a Pyrolytic Boron Nitride (PBN) heater and the proton beam, simultaneously.

After irradiation, a layer of $5 \mu \mathrm{m}$ was removed for the irradiated surface, and then the samples were back thinned to about $15 \mu \mathrm{m}$ using a wedge polisher. The TEM specimens were finally finished with ion milling at low angle to electron transparency. The cross-sectional TEM 
specimen was also prepared for the irradiated $\mathrm{ZrC}_{0.89}$. Post-irradiation microstructural characterization was conducted using a Philips CM200 transmission electron microscope (TEM) and a Cs-corrected FEI Titan TEM for Z-contrast image at an atomic resolution. The characterizations were performed to reveal irradiation-induced defects including dislocation loops, voids, dislocation networks or new precipitate phases. For comparison, the unirradiated microstructures of $\mathrm{ZrCs}$ were also examined using TEM.

\section{Results and discussions}

\subsection{Unirradiated microstructures}

The microstructures of the unirradiated $\mathrm{ZrC}$ with sub-stoichiometric $\mathrm{C} / \mathrm{Zr}$ ratios are generally free from fabrication defects, and the TEM images of unirradiated microstructures feature some small black dots likely due to the ion milling by using a $5 \mathrm{keV}$ Ar ions during sample thinning. $\mathrm{ZrC}_{0.95}$ contains a few of dislocation lines in the grains as shown in Fig. 9 (left), and the $\mathrm{ZrC}$ grains in $\mathrm{ZrC}_{1.05}$ have a moderate density Shockley partial dislocations and stacking faults. Graphite precipitates were observed for both hyper-stoichiometric $\mathrm{ZrC}$ compounds, with a seminodular structure in $\mathrm{ZrC}_{1.05}$ and a dendritic structure in $\mathrm{ZrC}_{1.17}$, as shown in Fig. 3, respectively. The portion of graphite precipitates in $\mathrm{ZrC}_{1.17}$ is much higher than that in $\mathrm{ZrC}_{1.05}$, which is consistent with the stoichiometry measurement.

\subsection{Dislocation loops}

The microstructures of irradiated $\mathrm{ZrC}$ are dominated with a high density of dislocation loops, as shown in Fig. 4 (a)-(e) at $\boldsymbol{g}=(200)$ near the zone axis of [011]. The mean size of dislocation loops is summarized in Fig. 4 (f). At the same irradiation condition, the dislocation loops in irradiated 
$\mathrm{ZrC}_{1.17}$ has the largest mean size. The thicknesses of the TEM specimens were estimated using convergent beam electron diffraction (CBED), and they are all very close to $80 \mathrm{~nm}$ for the areas of interest. It can be seen that as the $\mathrm{ZrC}$ matrix approaches to stoichiometric, the density of dislocation loop also increases slightly. High concentration of carbon vacancies in a substoichiometric $\mathrm{ZrC}$ can effectively inhibit the nucleation and further growth of dislocation loops by absorbing the displaced carbon interstitials at the vacancy sites. The significantly large dislocation loop size in the $\mathrm{ZrC}_{1.17}$ should be attributed to the low carbon vacancy concentration in the $\mathrm{ZrC}$ matrix and excessive carbon interstitials displaced from the nearby graphite precipitates. In general, the $\mathrm{ZrC}$ matrix with sub-stoichiometry offers an improved radiation resistance to microstructural alterations. Compared with the dislocation loop structure in neutron irradiated $\mathrm{ZrC}$, the mean size $(9.85 \mathrm{~nm})$ of dislocation loops in proton irradiated $\mathrm{ZrC}_{0.95}$ at 1125 ${ }^{\circ} \mathrm{C}$ fits well into the trend of dislocation loop diameter vs. irradiation temperature, which predicts a mean loop size of $\sim 12 \mathrm{~nm}$ at this irradiation temperature reported by Snead et al. [9].

TEM image of Fig. 4 (e) at near zone axis $<011>$ shows that the dislocation loops are aligned in two direction of the habit plant of $\{111\}$. More clearly, Fig. 5 shows part of a large edge-on dislocation loop formed on the $(\overline{1} 1 \overline{1})$ plane. To explicitly identify the nature of the dislocation loop, the lattice image was analyzed using Fourier-filtering. After masking the $\{111\}$ reflections and applying the inverse Fourier transformation, the lattice image notably shows a slight expansion (12\% in (111) direction) of the zirconium super lattice planes around the core of dislocation loop. The z contrast STEM image of Fig. 6 more clearly displays that the $\mathrm{Zr}$ lattice planes are expanded and distorted. However, due to the large $\mathrm{z}$ contrast difference between zirconium and carbon atoms, only the zirconium super lattice can be visualized. The image indirectly shows that the dislocation loop is probably a carbon core interstitial type loop. Based 
on the calculations from Morgan [16], the carbon atom has a much lower vacancy and interstitial formation and migration energies as compared with zirconium, the carbon atoms tend to be displaced easily and to migrate fast. To further determine whether the loops are faulted or prefect, the rel-rod diffractions at a two-beams condition near zone axis [011] were conducted, as shown in Fig. 7. No streak between the reflections of (200) and (1 $\overline{1} 1)$ or the satellite spots around reflections of $\{111\}$ were observed for any of those irradiated $\mathrm{ZrC}_{\mathrm{x}}$ specimens, which may indicate that the presences of dislocation loops in these specimens are mainly perfect loops.

Figure 8 shows the distribution of dislocation loops along the irradiation depth in the irradiated $\mathrm{ZrC}_{0.89}$, and the inset shows the dislocation loop structure at the damage peak that corresponds to a dose of about $20 \mathrm{dpa}$. It can be seen that as the dose increases, the dislocation loop size increase, but no voids were identified even in the radiation damage peak zone.

\subsection{Voids}

The void or bubble microstructures were carefully examined using a through-focus technique, and the irradiation induced faceted voids were only observed in the irradiated $\mathrm{ZrC}_{0.95}$ as shown in Fig. 9. The voids are aligned along the pre-existing dislocation lines. This enhanced void formation at the sub-grain boundaries or dislocation lines was also observed in electronirradiated Ni foils [17] and neutron irradiated LiF [18].

\subsection{Graphite precipitate effects}

Only the $\mathrm{ZrC}_{1.05}$ and $\mathrm{ZrC}_{1.17}$ contain free graphite precipitates in the form of flakes. As shown in Fig. 10, in the vicinity of graphite precipitates, the density of the dislocation loops in the $\mathrm{ZrC}$ matrix is much higher than that in the areas far from the graphite precipitates. It is speculated that 
the graphite precipitates serve as a strong source of knock on carbon interstitial atoms into $\mathrm{ZrC}$ matrix, and further these excessive interstitial carbon atoms are prone to clustering to form the dislocation loops in $\mathrm{ZrC}$ particularly as the concentration of carbon vacancies in the hyperstoichiometric is relatively low. In addition, the fact that some of large dislocation loops in Fig. 10 display fringes implies that those dislocation loops might be faulted loops. In contrast, the dislocation loops in the $\mathrm{ZrC}$ matrix away from the graphite precipitates display mainly as perfect loops.

\section{Conclusion}

The present results agree well with those from neutron irradiated $\mathrm{ZrC}_{0.93}$, reported by Snead, et al. In general, the $\mathrm{ZrC}$ is highly irradiation resistant at very high temperature. However, the irradiated microstructures can vary significantly with stoichiometry, graphite precipitates and pre-existing microstructural features. The irradiated $\mathrm{ZrCs}$ away from the graphite precipitates are all featured with perfect dislocation loops with varied mean sizes and densities. The $\mathrm{C} / \mathrm{Zr}$ ratio has a notable effect on the irradiation response of zone-refined ultra-high pure $\mathrm{ZrC}$, and the substoichiometric materials prove to have an improved irradiation resistant microstructure. No voids or bubbles were observed for any $\mathrm{ZrC}$ specimens except the $\mathrm{ZrC}_{0.95}$, and the voids in the irradiated $\mathrm{ZrC}_{0.95}$ can be attributed to the pre-existing dislocation lines or aligned planar defects as biased sinks by absorbing interstitials preferentially. It is concluded that the graphite precipitates formed from excess carbon are detrimental, and they can dramatically increase the size of dislocation loops and the density of loops in the vicinity of graphite precipitates in the ZrC phase. 


\section{Acknowledgement}

The present study is the result of "Deep Burn: Development of Transuranic Fuel and Fuel Cycles for High Temperature Gas-Cooled Reactor," supported by the US Department of Energy. The authors would like to thank Y. Katoh, J. D. Hunn of the Oak Ridge National Laboratory for providing the zone-refined $\mathrm{ZrC}$ materials. 


\section{Captions:}

Fig. 1. Phase Diagram of Zr-C system.

Fig. 2. Calculated radiation damage profile (left), and irradiation temperature distribution (right).

Fig. 3. Graphite precipitates in hyper-stoichiometric $\mathrm{ZrC}$

Fig. 4. (a)-(e): dislocation loop structures in irradiated $\mathrm{ZrC}_{\mathrm{x}}$ with varied $\mathrm{C} / \mathrm{Zr}$ ratios, and (f): summary of mean dislocation loop size.

Fig. 5 (a) HR-TEM image of dislocation loop, (b) diffraction pattern at zone axis [011] and (c) inverse FFT TEM image from (b) after applying mask filter.

Fig 6. Z-contrast STEM image of the core of a dislocation loop.

Fig. 7. Two-beam condition diffraction pattern with $g=\overline{3} 1 \overline{1}$ near zone axis [011] from the irradiated $\mathrm{ZrC}$.

Fig. 8. Cross sectional TEM image of the irradiated $\mathrm{ZrC}_{0.89}$.

Fig. 9. Unirradiated microstructure of $\mathrm{ZrC}_{0.95}$ (left) and void structure in irradiated $\mathrm{ZrC}_{0.95}$ (right). Fig. 10. Irradiated microstructures in the vicinity of graphite precipitate. 


\section{References}

Table 1. List of $\mathrm{ZrC}_{\mathrm{x}}$ with five stoichiometries.

\begin{tabular}{|c|c|c|c|c|}
\hline Sample & $\begin{array}{c}\text { Target } \\
\text { Stoichiometry }\end{array}$ & $\begin{array}{c}\text { Measured } \\
\text { overall C/Zr }\end{array}$ & $\begin{array}{c}\text { Measured C/Zr in } \\
\text { matrix using WDS }\end{array}$ & \multirow{2}{*}{ Dimension } \\
\hline 1 & $\mathrm{ZrC}_{0.8 \pm 0.05}$ & 0.84 & $0.81 \pm 0.02$ & \\
\cline { 1 - 3 } 2 & $\mathrm{ZrC}_{0.9 \pm 0.05}$ & 0.89 & $0.84 \pm 0.03$ & \multirow{2}{*}{$3 \mathrm{~mm}$ rod } \\
\hline 3 & $\mathrm{ZrC}_{1.0 \pm 0.05}$ & 0.95 & $0.92 \pm 0.03$ & \\
\hline 4 & $\mathrm{ZrC}_{1.1 \pm 0.05}$ & 1.05 & $0.95 \pm 0.01$ & \\
\hline 5 & $\mathrm{ZrC}_{1.2 \pm 0.05}$ & 1.17 & $0.98 \pm 0.01$ & \\
\hline
\end{tabular}




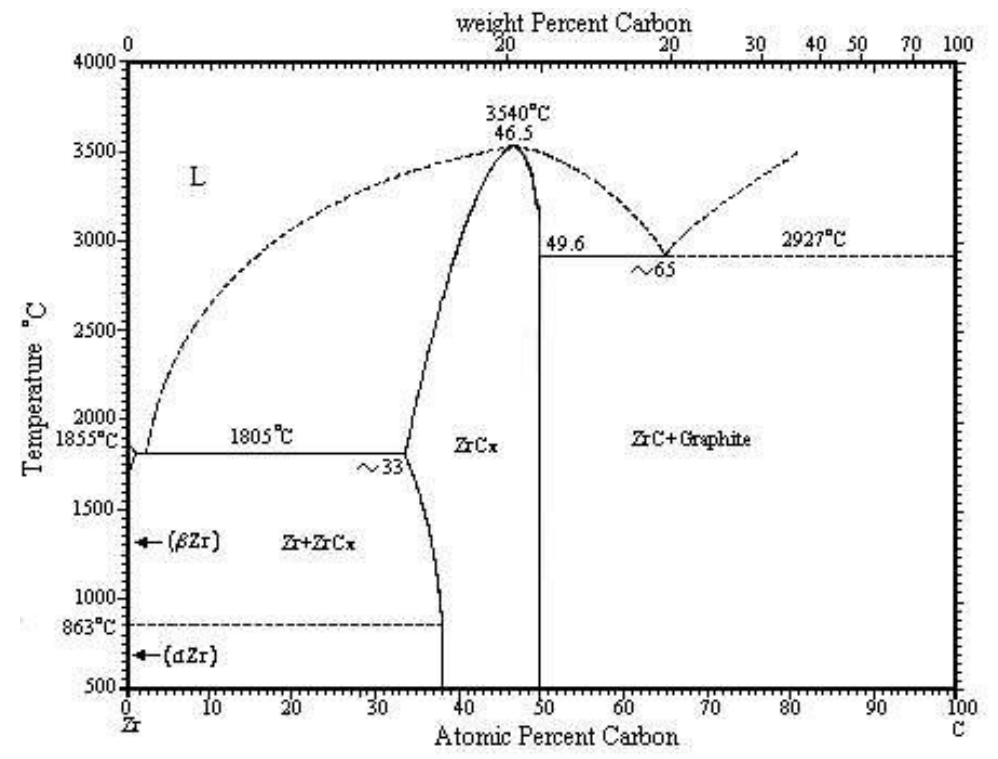

Fig. 1. Phase Diagram of Zr-C system, modified from [11]. 

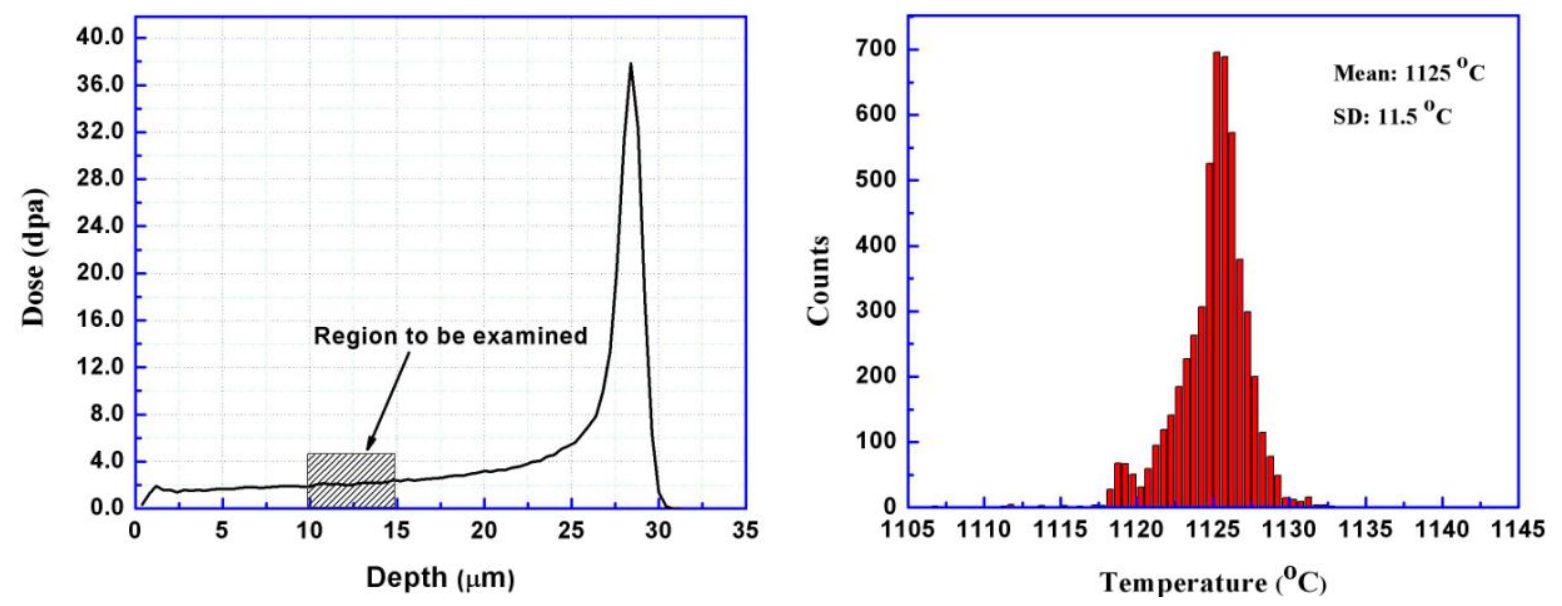

Fig. 2. Calculated radiation damage profile (left), and irradiation temperature distribution (right). 


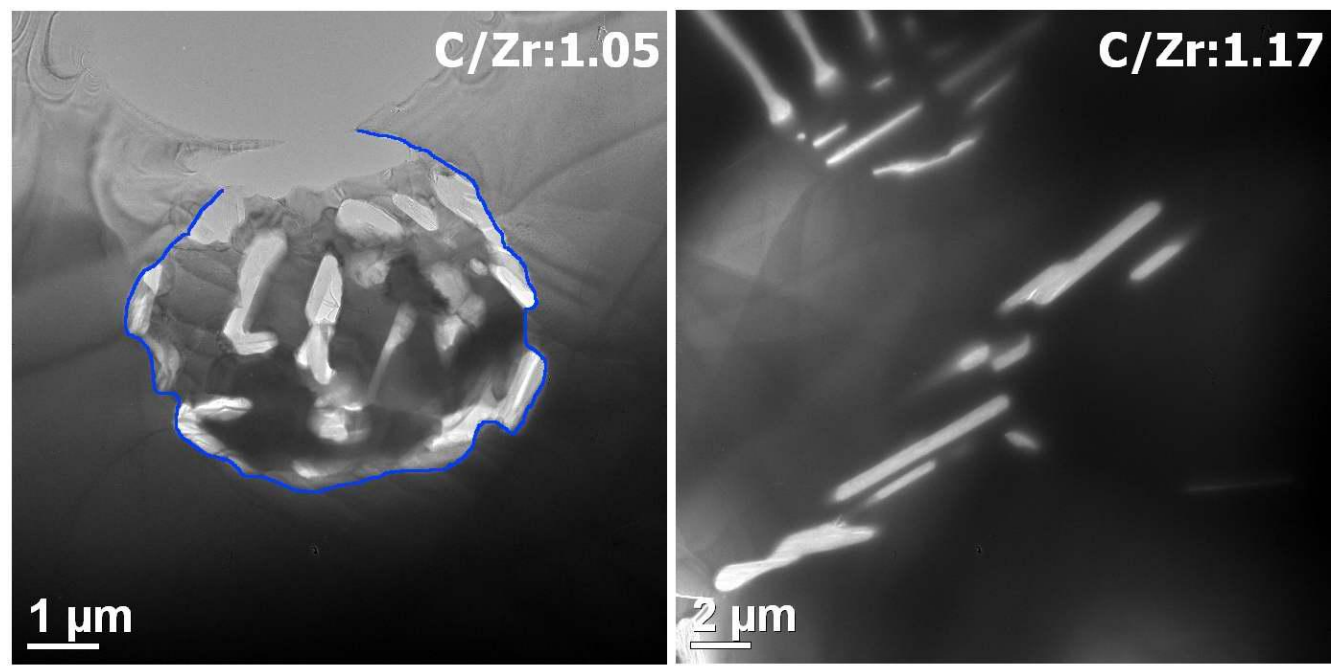

Fig. 3. Graphite precipitates (in bright) in hyper-stoichiometric $\mathrm{ZrC}$. 

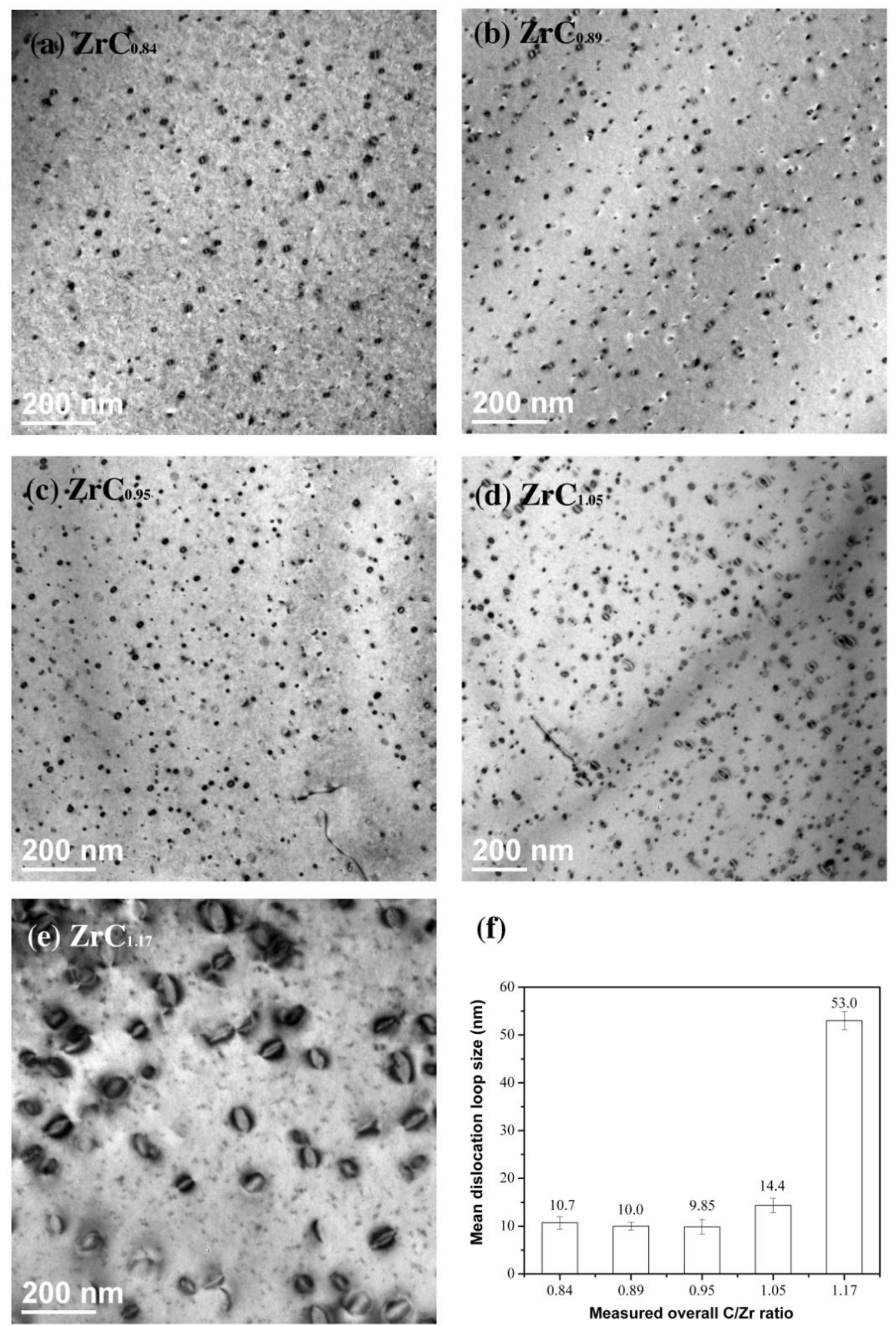

(f)

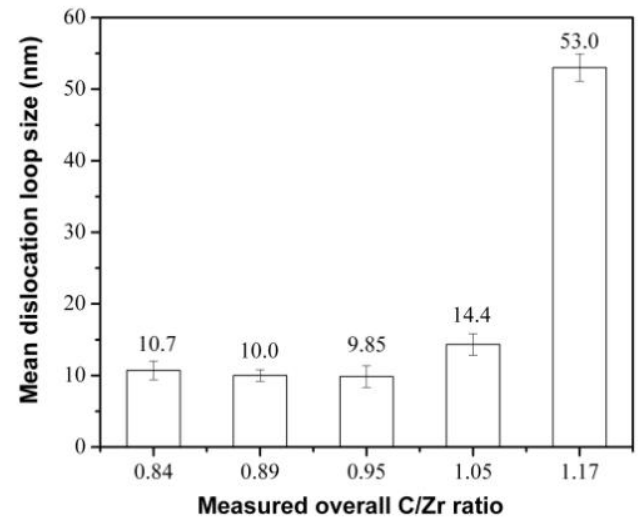

Fig. 4. (a)-(e): dislocation loop (black dots or elliptical loop) structures in irradiated $\mathrm{ZrC}_{\mathrm{x}}$ with varied $\mathrm{C} / \mathrm{Zr}$ ratios, and (f): summary of mean dislocation loop size vs. $\mathrm{C} / \mathrm{Zr}$ ratio. 

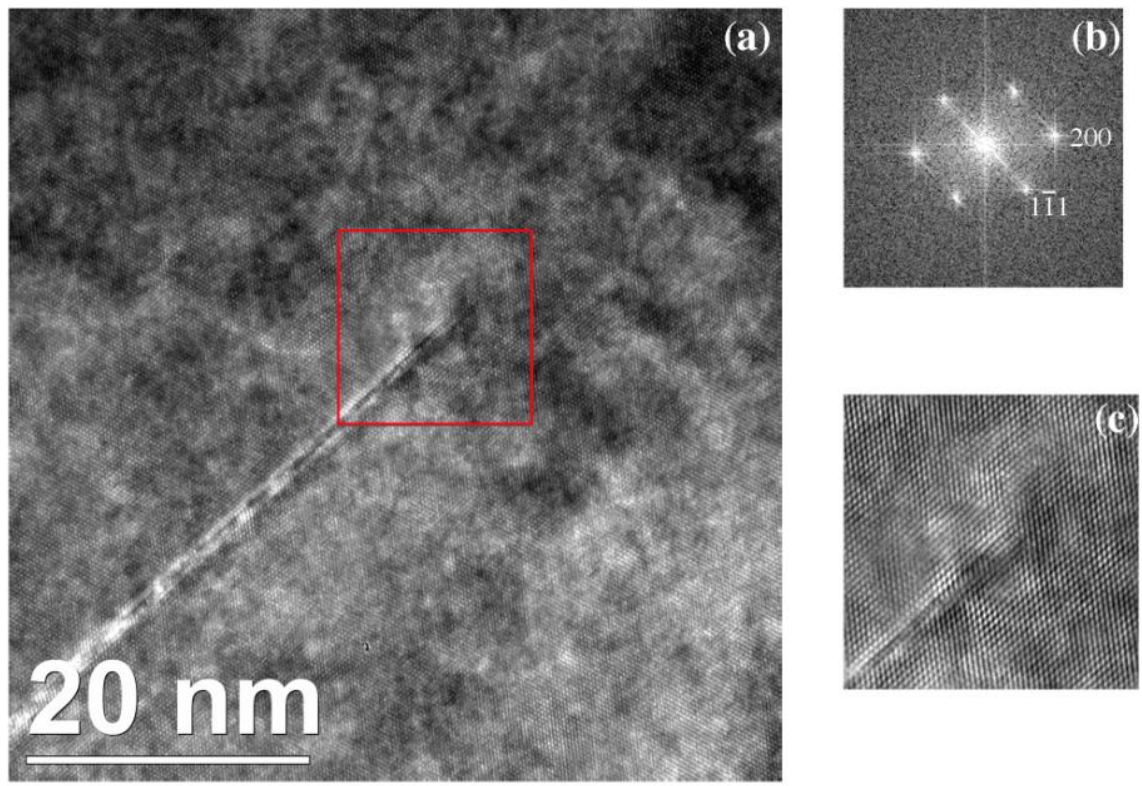

Fig. 5 (a) HR-TEM image of dislocation loop as illustrated by the line of strained lattice planes, (b) diffraction pattern at zone axis [011] and (c) inverse FFT TEM image from (b) after applying mask filter. 


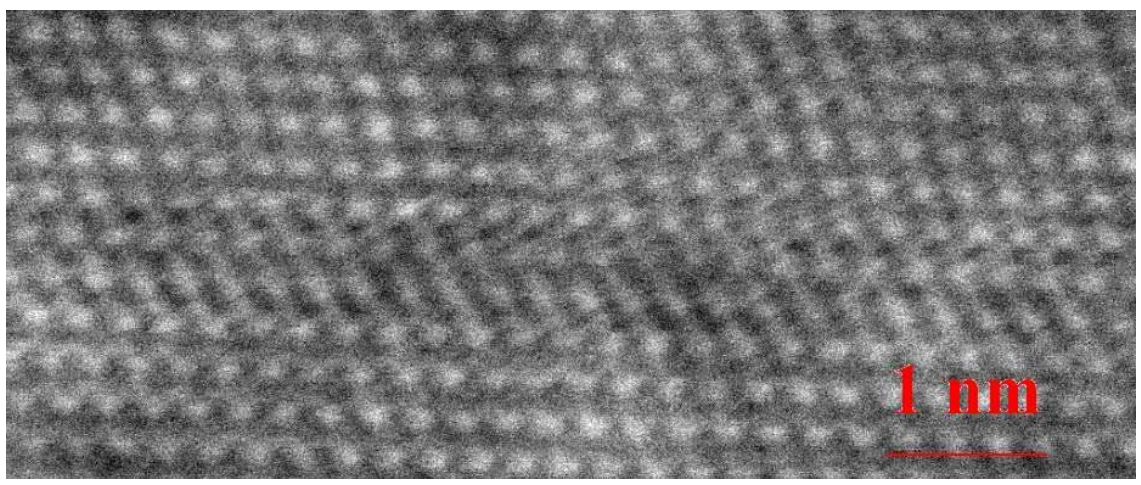

Fig 6. Z-contrast STEM image of the core of a dislocation loop, and each dot represents one $\mathrm{Zr}$ atom and the image is at the [011] zone axis. 


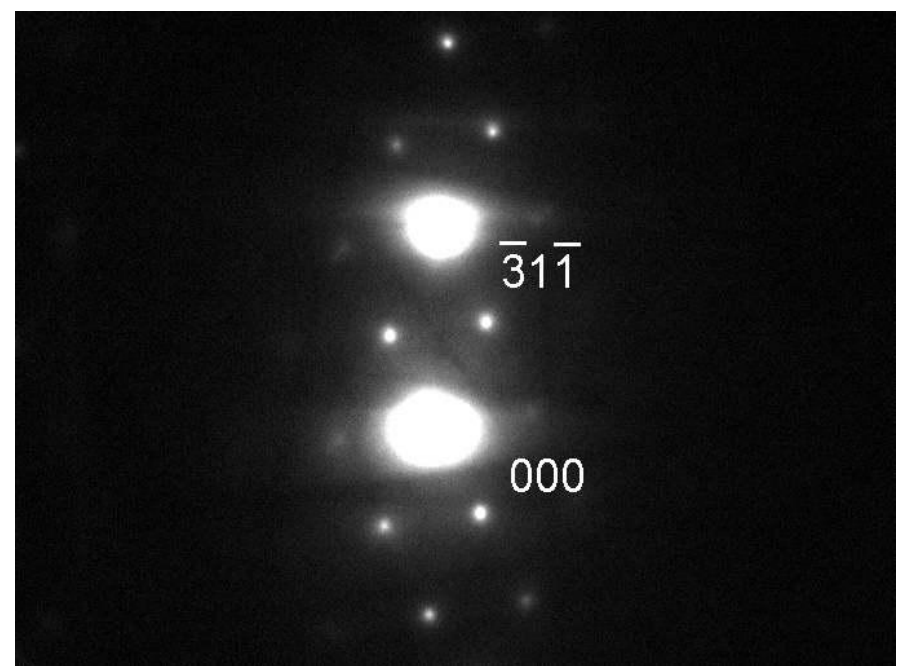

Fig. 7. Two-beam condition diffraction pattern with $g=\overline{3} 1 \overline{1}$ near zone axis [011] from the irradiated $\mathrm{ZrC}$ and no relrod streaks was identified. 


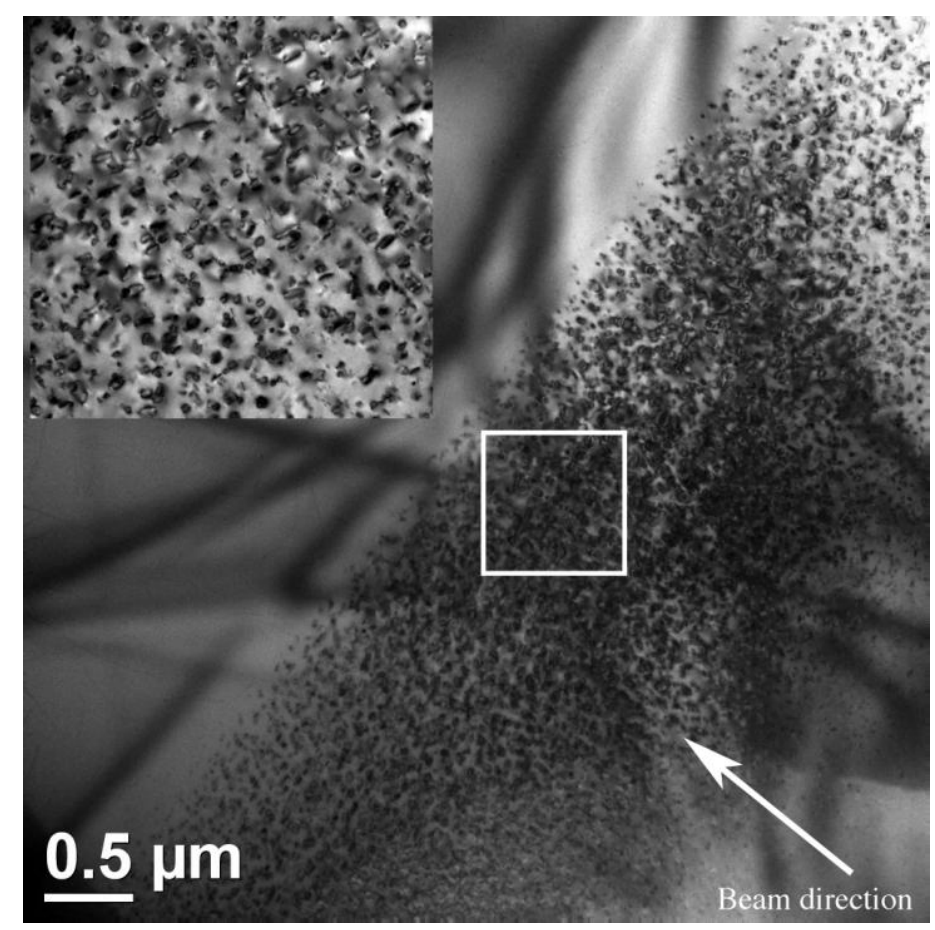

Fig. 8. Cross sectional TEM image of the irradiated $\mathrm{ZrC}_{0.89}$, and inset is zoomed in image of the area in the white square and the white arrow indicate the irradiation direction of the proton beam. 

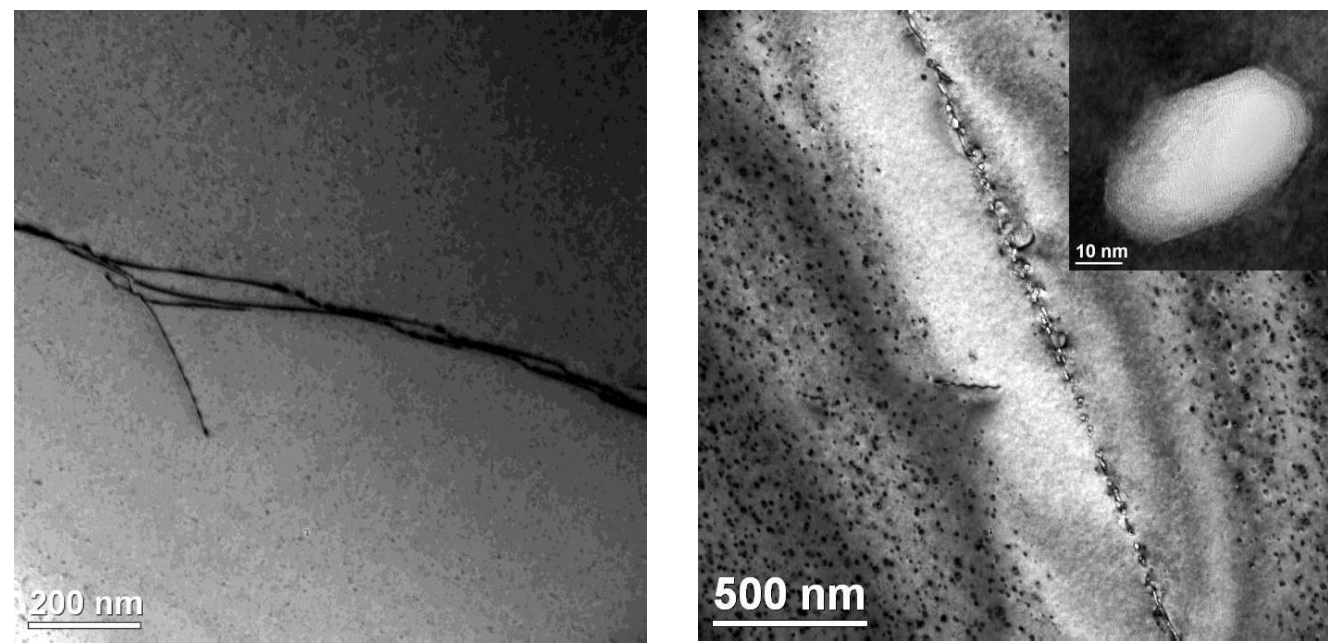

Fig. 9. Left is the unirradiated microstructure of $\mathrm{ZrC}_{0.95}$ and the black lines represent the dislocation lines. Right is the void structure in irradiated $\mathrm{ZrC}_{0.95}$ and the inset is a zoomed-in image of one void aligned at the pre-existing dislocation line. 

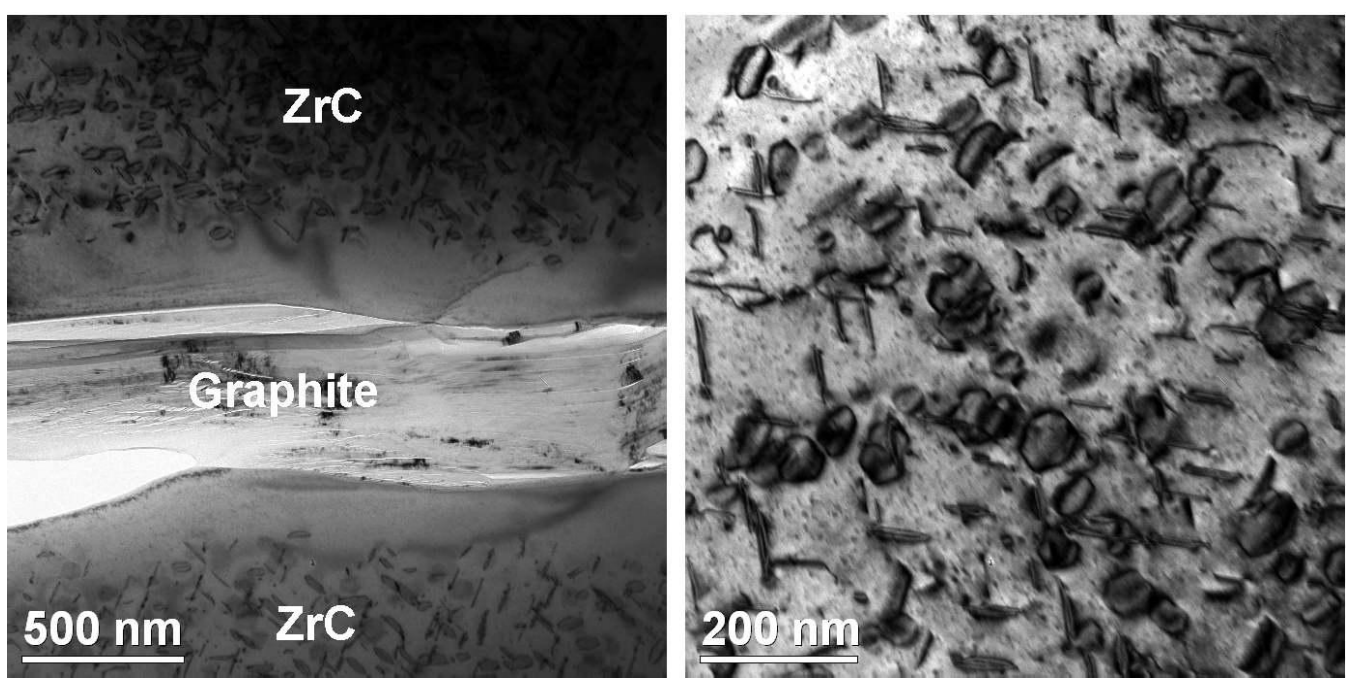

Fig. 10. Irradiated microstructures in the vicinity of graphite precipitate.

\section{Reference}

[1] Y. Katoh, G. Vasudevamurthy, T. Nozawa, L. Snead, J. Nucl. Mater., 441 (2013) 718-742.

[2] R.M. Versluis, F. Venneri, D. Petti, L. Snead, D. McEachern,2008 4th International Topical Meeting on High Temperature Reactor Technology, HTR 2008, 1, (2008) 167-170.

[3] R. Andrievskii, V. Savin, V. Markin, V. Spravtsev, A. Shevchenko, Neorg. Mater., 14 (1978) 675-679.

[4] D.A. Dyslin, R.E. Moore, H.E. Robertson, Irradiation damage to non-fissionable refractory materials, ORNL, 4480.

[5] J. Gan, M.K. Myer, R.C. Birtcher, T.R. Allen, J. ASTM Int., 3 (2006) 358-365.

[6] D. Gosset, M. Dolle, D. Simeone, G. Baldinozzi, L. Thome, J. Nucl. Mater., 373 (2008) 123-129.

[7] M. Kovalchenko, Y. Rogovoi, Neorg. Mater., 9 (1973).

[8] Y. Yang, C. Dickerson, H. Swoboda, B. Miller, T. Allen, J. Nucl. Mater., 378 (2008) 341-348.

[9] L.L. Snead, Y. Katoh, S. Kondo, J. Nucl. Mater., 399 (2010) 200-207.

[10] E.K. Storms, P. Wagner, High. Temp. Sci., 5 (1973) 454-462.

[11] O.M. Barabash, Y.N. Koval, Crystal structure of metals and alloys, Naukova Dumka, Kiev, Ukraine, 1986.

[12] C. Liu, b. Liu, Y.L. Shao, Z.Q. Li, C.H. Tang, J. Am. Ceram. Soc., 90 (2007) 3690-3693.

[13] G.H. Reynolds, J. Nucl. Mater., 50 (1974) 215.

[14] S. Ueta, J. Aihara, A. Yasuda, H. Ishibashi, T. Takayama, K. Sawa, J. Nucl. Mater., 376 (2008) 146151.

[15] J.F. Ziegler, J.P. Biersack, U. Littmark, The stopping and Range of Ions in Solids, Pergamon Press, New York, 1996.

[16] S. Kim, I. Szlufarska, D. Morgan, J. Appl. Phys., 107 (2010) 053521.

[17] D.I.R. Norris, Phil. Mag. , 23 (1971) 135.

[18] D. Nenow, S. Gueleva, Phys. Stat. Sol., (a) 55 (1979) 489. 